\title{
TERRITORIO ECONÓMICO Y POLÍTICO DEL SUR DE LA CONTESTANIA IBÉRICA'
}

\author{
POR \\ JUAN A. SANTOS VELASCO \\ Escuela Española de Historia y Arqueología en Roma. CSIC
}

\begin{abstract}
RESUMEN
El propósito del presente estudio es establecer una nueva delimitación de la Contestania ibérica en su parte sur, en los alrededores de la Ilici prerromana. Nuestra hipótesis es la posible gestación de una ciudad-estado en el SE de la Península Ibérica, durante los siglos VI-III a. C. Nos basamos en la distribución espacial de las evidencias arqueológicas, como la cerámica pintada, las monedas y la escultura en piedra.
\end{abstract}

\section{SUMMARY}

The purpuse of the present study is to establish a new delimitation of the Iberian Contestania, in its south part, around the preroman Ilici. Our hypothesis is the posible gestation of a city-state in the S.E. of the Iberian Peninsula during the VI-III centuries B.C. We based on the spacial distribution of the archeological evidence, as the painted pottery, coins and stone sculpture.

1 Este trabajo se integra en el proyecto «Imagen, mito y sociedad en el mundo ibérico: Alicante y Murcia». Programa PB 89006.C02.01, financiado por la DGICYT. 
Han pasado veinte años desde que apareciera la primera síntesis sobre el mundo ibérico, planteada como una obra de carácter histórico, que abordara, entre otros, un tema tan espinoso como el de la delimitación del territorio de uno de los grupos culturales citados por las fuentes literarias; me refiero a Contestania Ihérica de E. Llobregat (1972). Esta obra ha sido, desde entonces, básica para cualquier estudioso del iberismo y hoy sigue siendo un punto clave de referencia para aquellos investigadores que se acercan a la problemática arqueológica de las culturas prerromanas del Levante y Sureste de nuestra península. No obstante, han transcurrido dos décadas y contamos ahora con una mayor y mejor sistematizada documentación, aparte de unos resortes teóricos y metodológicos, que no existían en la investigación española de comienzos de los setenta. Ello permite, desde una nueva perspectiva, proponer nuevas hipótesis que se irán desarrollando a lo largo de las páginas siguientes.

\section{PRESUPUESTOS PRELIMINARES}

Una de las cuestiones de más debatida actualidad es la caracterización de la estructura social del mundo ibérico. Tema sobre el que se viene trabajando con particular intensidad desde hace algo más de una década, y que ha supuesto un salto cualitativo, de la mayor trascendencia, para la comprensión de los cimientos estructurales que configuraron aquellos grupos culturales, en el marco global del mundo prerromano mediterráneo.

Hay un aspecto de este debate que nos interesa particularmente: la concreción, en el sureste, de formas estatales aristocráticas arcaicas, sobre la base de un entramado territorial protourbano. Tema que ya he tratado, en sus líneas generales, con anterioridad (en prensa, a) y del que ahora quisiera abordar uno de sus aspectos, los criterios para la delimitación de un territorio en torno a una de aquellas protociudades, en concreto la de Elche.

Previo a esto conviene dar un repaso, aunque sea somero, a algunos de los datos con los que contamos para hablar de rango de protociudad, en el sureste, en época ibérica.

1) Urbanismo y espacios públicos se encuentran en un momento de desarrollo incipiente, al menos por lo que conocemos hoy. Podemos citar poco más que las murallas, aunque recientes descubrimientos están sacando a la luz una realidad más compleja.

Existen recintos como El Oral, de planta cuadrada, calles que se cruzan casi en ángulo recto, y con una amplia zona rectangular abierta (Abad, L., 1985-87, 60).

Las excavaciones de Sagunto demuestran la existencia de un barrio marítimo, en la zona del Grau Vell, que sería el antiguo puerto, originado por la actividad comercial que Plinio refleja en sus escritos, al llamar a Sagunto "ciudad opulentísima» (Hist. XXI, 7, 1-3, en Aranegui, C., 1980, 62).

En Cástulo existe lo que pudo ser un barrio industrial con alfares, hornos y escorias de fundición (Blázquez, J. M. y García Gelabert, M. A., 1986-87).

Sabemos que la jerarquía de los asentamientos conlleva la distinta funcionalidad de los mismos, que en muchos casos son hábitats especializados en determinadas actividades. Caso de las torres andaluzas (Ruíz, A., 1978) o de lugares como Puntal dels Llops (Valencia), una unidad funcional compleja que se levanta en una sola fase constructiva, a partir de un plan preestablecido (Bernabeu, J. et al., 1986, 321). 
No olvidemos, entre los recientes trabajos, el yacimiento de Alt de Benimaquia (Denia, Valencia), donde se han puesto al descubierto lugares para la elaboración de vino, siendo interpretado, por sus excavadores, como un centro residencial de un personaje de élite. Se trata de un hábitat de apenas media ha., con una fortificación con seis bastiones construido, ex novo, en la primera mitad del siglo Vı a. C., y cuya ocupación dura tan sólo cincuenta años. Es un lugar donde se produce, en una fecha antigua, un bien de consumo claramente vinculado a las implicaciones sociales e ideológicas que plantea la aculturación a través del vino, entre las élites indígenas (Gómez Bellard, C. y Guerin, P., en prensa).

Pero donde más evidente se hace la diferente funcionalidad del hábitat y sus consecuencias sociológicas es en la localización de los santuarios. En la cuenca del Segura se encuentran junto a hábitats importantes, en una triple asociación santuario/poblado/monumentos funerarios, que nos advierte sobre la presencia de una élite que habita sólo en determinados centros, a los que además se asocia el culto y la vida religiosa (Santos Velasco, J. A., 1989a). Situación semejante a la de Levante, en lo que Aranegui denomina santuarios periurbanos (en prensa).

No podemos pasar por alto, en este apartado, un reciente trabajo sobre el Cerro de los Santos, donde no sólo se sugiere la imagen ibérica en piedra, como la imagen de la clase dominante, sino que se argumenta la hipótesis de un santuario transnacional, situado en el límite de dos pentápolis, al estilo de lo que ocurre en Etruria y Grecia (Ruano, E., 1987, 208).

Por las fuentes, también sabemos que ciudades como Sagunto tenían templos, como en este caso dedicado a Diana (Plinio, Hist. Natural, XXI, 216, en C. Aranegui, 1988, 60). Por su parte, las estructuras de la Illeta de Campello, datables en el siglo IV a. C. e interpretadas como templos (Llobregat, E., 1988, 141), han sido reinterpretadas, más recientemente, como una posible casa-palacio (Almagro, M. y Domínguez de la Concha, F., 1990).

2) Los asentamientos ibéricos son de pequeño y mediano tamaño (Coimbra del B.A.: 1,6 has., Ilici: 9 has.). Ahora bien, tengamos en cuenta que Ampurias, incluyendo la Palaiopolis, cubre 4,5 has., y que existen centros indígenas, como Cástulo, con 44 has. (Almagro, M., 1986, 26).

Se aprecian además dos fenómenos significativos:

a) Una gran reestructuración del hábitat a mediados o fines del siglo $\vee$ a. C. ${ }^{2}$, acompañada muy probablemente de un aumento demográfico, a juzgar por la gran cantidad de yacimientos datables a fines del siglo y primera mitad de IV a. C. Ambas cuestiones coinciden con el desarrollo de las fuerzas productivas y la consolidación de la cultura ibérica (Fase Plena), que es precisamente el momento de afirmación de las aristocracias arcaicas, perceptible en el registro arqueológico a través de las tumbas principescas (Santos Velasco, J. A., 1989b).

b) El hábitat está fuertemente jerarquizado, como sabemos por los estudios del valle del Ebro (Burillo, F., 1986), Andalucía oriental (Ruíz, A., 1978), Levante (Geruin, P., et al., 1989) y sureste (Santos Velasco, J. A., 1989a).

En las fuentes literarias abundan datos que refrendan esta situación, como el conocido caso del régulo Culchas que gobierna en 207 a. C. sobre 28 ciudades; o el caso de los dobles topónimos como Saitabi/Saetabicola u Obulco/Obulcula, del mismo modo que la asociación entre nombres de ciudades y de pueblos (Basti/bastetanos u Oretum/oretanos) son todos síntomas de un desarrollo protourbano, si no plenamente urbano (Jacob, P., 1985, 51).

2 Caso del traslado de la población de El Oral a La Escuera (ABAD, L., 1987). 
En el caso que estamos tratando, grosso modo, las cuencas media y baja del Segura, se reconocen unos centros que articulan el poblamiento desde el siglo VI al II a. C. (La Encarnación, El Cigarralejo, Verdolay, entre otros). Pero si en ellos reconocemos centros protourbanos no podemos decir lo mismo en cuanto a su identificación con un estado, que perviviera políticamente más de tres siglos por varias razones, que señalé en su momento (Santos Velasco, J. A., 1989a).

- Lo reducido de sus tamaños, de lo que se deduce lo reducido de su población.

- Los hallazgos de sus necrópolis permiten suponer que con el tiempo iba variando la importancia de su ocupación, entre los siglos v y II a. C. Por lo que también el peso político y económico de estos centros debió de ir variando. Hecho que puede ser fortuito, depender de situaciones coyunturales, o tener una explicación más profunda, dentro de un complejo sistema político-social de alcance regional. Lo que nos lleva a plantear la existencia de un centro mayor que actue, en este área, como «capitalidad».

En este sentido en la bibliografía reciente se ha planteado la idea de la existencia de capitales supracomarcales, Elche y Bocairente (Domínguez Monedero, A., 1984, 150) o Elche y Saitabi (Gil Mascarell, M., 1980, 233), que debieramos entender a partir de la hipótesis de una concentración paulatina del poder político, entre los siglos VI-III a. C., a medida que se consolida una organización arcaica de estados aristocráticos, territorialmente pequeños que, en el caso preciso que nos ocupa, debió tener su centro en Elche.

\section{CRITERIOS PARA LA DEFINICIÓN DEL TERRITORIO DE ILICI}

El punto anterior nos introduce en la cuestión siguiente: cómo identificar los centros económicos y políticos que organizan el ordenamiento del hábitat. Cuestión que está todavía por resolver, pero de la que contamos con algunos indicios, en otras áreas culturales.

En un reciente trabajo se ha identificado $\mathrm{S}$. Miguel de Liria, con más de 10 has. de superficie, como el centro de un área extensa, que engloba pequeños asentamientos diseminados en la llanura y fortines situados a lo largo de la sierra Calderona, que sirven de límite o «frontera» al territorio bajo su control (Guerin, P. et al., 1989).

Una realidad similar existe en la actual provincia de Jaén, donde se identifican tres grandes oppida, que ordenan el poblamiento: Obulco, Cástulo y Toya. Lo que no quiere decir que sean tres estados diferentes, por los vínculos que se establecen entre los dos últimos centros en las fuentes escritas (Ruíz, A., et al., 1985-87) ${ }^{3}$.

Este caso es de sumo interés porque nos ayuda a entender mejor el referido al Segura, donde estamos lejos de una comprensión global precisa de esta problemática, pero donde se pueden ir perfilando algunas cuestiones. Centros como El Cigarralejo, Verdolay, Coimbra del B. A. y otros son de similar importancia, por tamaño, por los datos de sus necrópolis (con monumentos funerarios), porque todos están asociados a santuarios, y todos parecen controlar una amplia comarca natural (Santos Velasco, J. A., 1989a). El dilema es corroborar que se trata de lugares dependientes de otro mayor, que pudo ser Elche. Unico centro de la región con suficiente entidad para ello, en las cuencas media y baja del Segura.

3 En este trabajo los autores ponen de manifiesto la falta de datos que todavía tenemos, lo que impide establecer una clara relación territorio económico/territorio político. 
Ya se señaló la unanimidad de la investigación en cuanto a otorgar a llici una relevancia de carácter supracomarcal, de control de lo que sería el sur de la Contestania, y los datos arqueológicos que estamos manejando en la actualidad, sobre el poblamiento, las necrópolis, etc., conducen a plantear este tema, pudiendo no sólo ratificarlo, sino además proponer una nueva delimitación del territorio de la antigua Ilici ibérica.

La importancia de este yacimiento viene dada por varias razones, entre otras, su extensión que con 9,8 has. (Almagro, M., 1988) supera con creces las de otros centros regionales importantes como El Cigarralejo, Coimbra del B. A. o La Escuera; y la continuidad de su poblamiento, ininterrumpido desde el siglo VI a. C. a época romana.

Asimismo, La Alcudia fue un centro de gran importancia durante la Fase Ibérica Antigua. Pensemos que allí hubo varios monumentos funerarios en forma de torre (Chapa, T., 1986, 246) y que es el único lugar que documenta todos los tipos iconográficos de la escultura zoomorfa (figura 1). Por otra parte, Chapa Brunet mantiene la hipótesis de que en la zona del Vinalopó hubiera un taller de escultura de ámbito comarcal, pues los leones de Sax, Monforte del Cid y Elche, y en menor grado los de La Albufereta y Villajoyosa, son con toda probabilidad piezas del mismo taller, con un área de dispersión entre el Vinalopó y la costa sur alicantina (Chapa, T., 1986, 260, ver figura 1).

La distribución de la escultura zoomorfa señala unos ámbitos geográficos que se definen mejor si tomamos algunos de sus tipos, toros del grupo B, leones del período antiguo, caballos, lobos, esfinges y grifos (ver Chapa, T., 1986), que se reparten fundamentalmente entre los ejes del Júcar y del Vinalopó/Segura, encuadrando un área sobre la que debemos tener presente dos puntos:

a) Las sierras alicantinas separan la Contestania en sentido este/oeste, de una manera na-

Figura 1.-Dispersión de la escultura zoomorfa (según Chapa Brunet, 1984) y división del norte y sur de la Contestania (según Domínguez Monedero, 1984). 1: Turís; 2: Alcoy; 3: Corral de Saus; 4: Bocairente; 6: Pozo Cañada; 7: Ontur; 8: Coimbra del Barranco Ancho; 9: Villena; 10: El Monastil; 11: Villajoyosa; 12: La Alcudia; 13: Benidorm; 14: Guardamar; 15: El Molar; 16: Cabecico del Tesoro; 17: El Cigarralejo; 18: Coy.

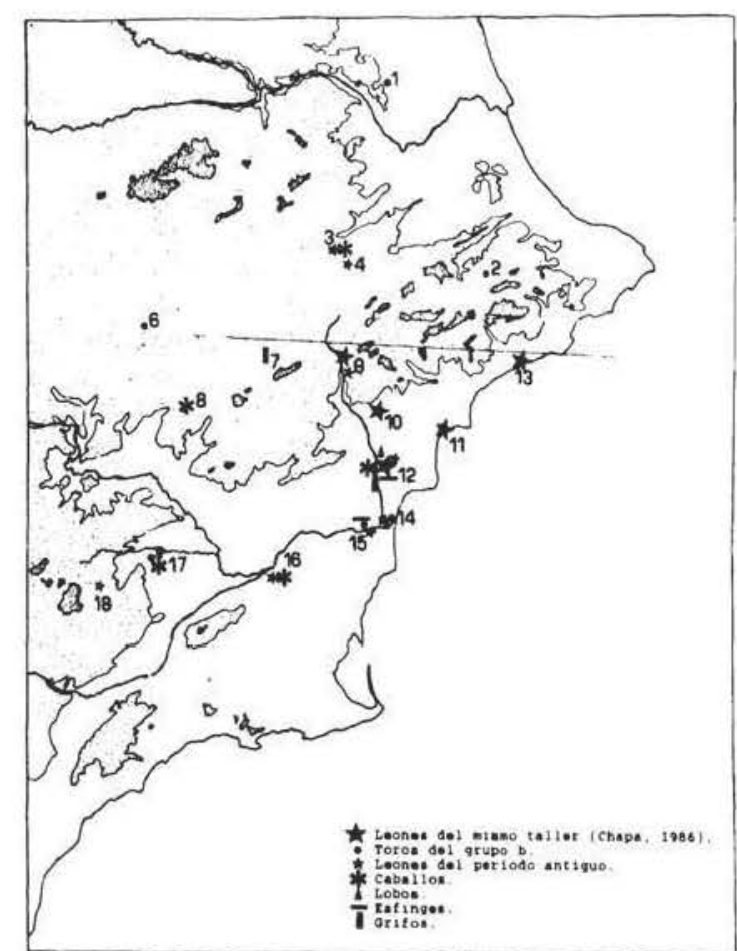


tural. Al norte la zona de montaña, con centro en Bocairente y al sur el llano con centro en Elche (Domínguez Monedero, A., 1984).

b) Las esculturas sobrepasan la línea Vinalopó/Segura y las hallamos hacia el interior, por la cuenca del Segura, hasta el Cigarralejo.

De estos datos se puede deducir que en la Fase Antigua la Contestania es un territorio mal definido, lo cual no es de extrañar si consideramos que el término Contestania sólo aparece en las fuentes escritas más modernas, mientras que las más antiguas hablan de los mastienos, en esta zona de la península (Abad, L., en prensa).

No obstante, ya en esas fechas, Elche se manifiesta como un punto de referencia importante, cuya influencia se extendería por la costa sur alicantina, Vinalopó y cuenca baja del Segura, pero la ausencia de más datos impide saber si ese influjo es económico, político o ambos a la vez.

La documentación arqueológica, sobre fechas más recientes, concreta un ámbito territorial mejor definido.

1) La distribución de las monedas de la ceca de llici, en época altoimperial (reinados de Augusto y Tiberio), demuestra que el área de expansión económica de esta ciduad está entre las costas meridionales alicantinas y las cuencas media y baja del Segura, región de Murcia (figuras 2 y 3, ver Llorens, M., 1987). Es una evidencia tardía, pero concuerda con la dispersión de los hallazgos más importantes de vasos pintados de estilo de Elche (entre fines del s. III a. C. y el cambio de era $)^{4}$. Desde el centro neurálgico de Ilici, la mayor concentración se halla en el Vinalopó y la cuenca del Segura, hasta Archena (figura 4).

Hecho que, a su vez, concuerda con la dispersión de los kalathoi de los tipos del Cabecico del Tesoro (figura 5). Entre las trece piezas estudiadas recientemente, ocho son de pleno estilo ilicitano o afines, datables entre la primera mitad del siglo II a. C. y 100 a. C. (Conde, Ma J., 1990).

2) Los testimonios del uso de la escritura en alfabeto griego jonio, que conocemos como
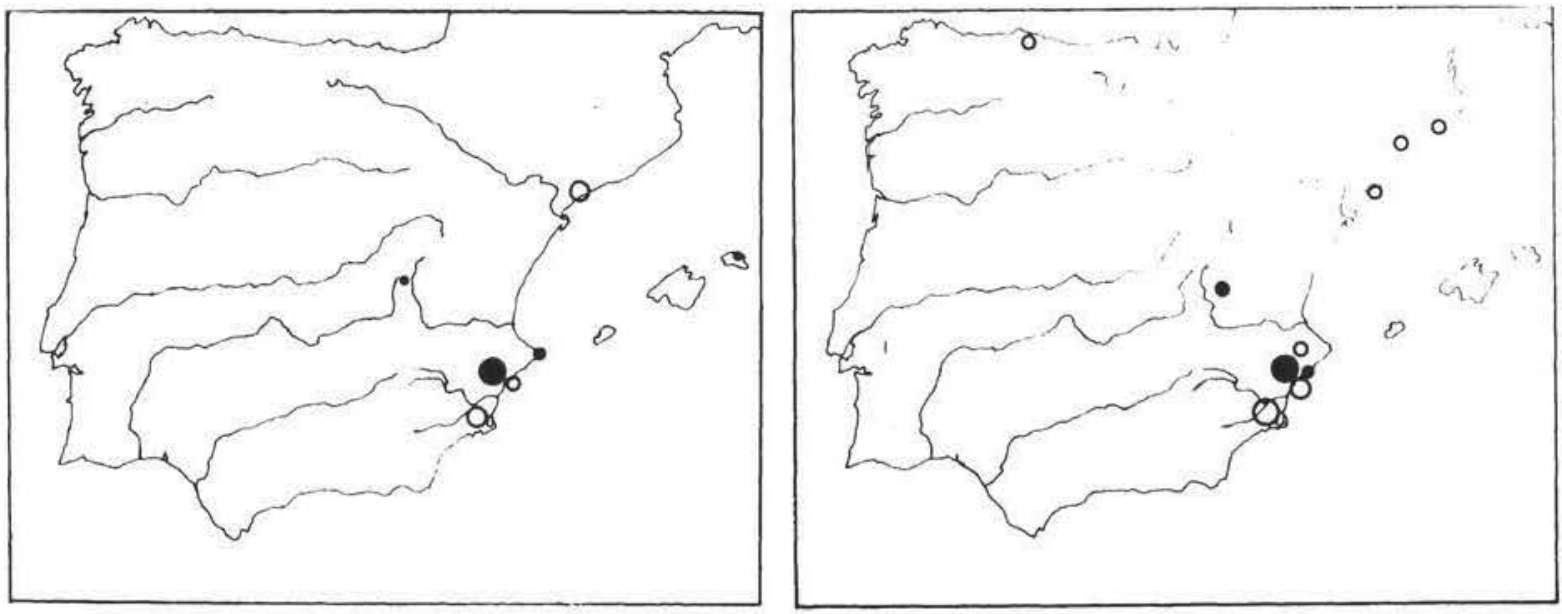

Figuras 2 y 3.-Dispersión de monedas de la ceca de llici durante los reinados de Augusto y Tiberio (según Llorens, 1987).

4 Estos datos han sido recogidos en La céramica ibérica de estilo Elche-Archena, del doctor M. MENÉNDEZ, a quien quiero agradecer el haberme proporcionado los mismos. 


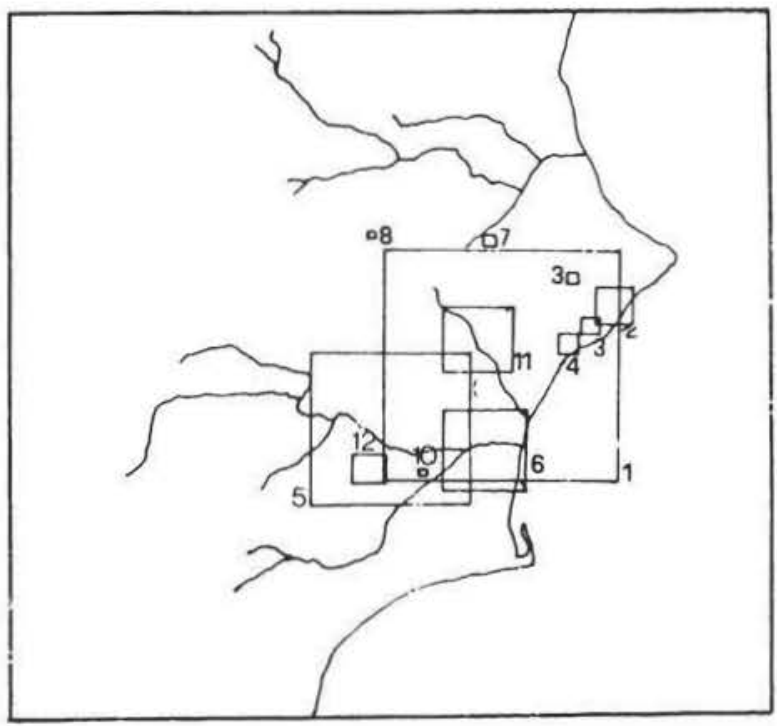

Figura 4.-Distribución porcentual de los vasos pintados de estilo Elche. 1: La Alcudia; 2: Tossal de Polop; 3: La Serreta; 4: Tossal de Manises y La Albufereta; 5: Cabezo del Tío Pío; 6: Cabecico del Tesoro; 7: Corral de Saus; 8: Hoya de Sta. Ana: 9: Pozo Moro; 10: Alhama: 11: El Monastíl; 12: El Cigarralejo.

greco-ibérico, se encuentran en el mismo área (figura 6) y nos llevan a contextos arqueológicos ya dentro del siglo IV a. C., durante la Fase Ibérica Plena.

3) Por último, entre los siglos IV y II a. C. se documentan una serie de objetos, relacionados con el culto, que aportan nuevos datos: los pebeteros con forma de cabeza femenina y otras terracotas, relacionadas con Tanit o con una diosa local de la muerte y la fecundidad, entre las que pudo darse un posible sincretismo. Han sido analizadas por Marín Ceballos (1987), quien admite un alto grado de asimilación del culto a Tanit, en el sureste español, debido a que en esta zona de la península se documentan en número abundante y particularmente en santuarios y necrópolis 5 .

Conjuntos importantes de las mismas los encontramos distribuidos, una vez más, por la costa sur de Alicante y las cuencas del Vinalopó y bajo Segura (figura 7). Esta zona se constituye en un área central, rodeada a su vez de una serie de hallazgos vinculados, como la figura de la necrópolis de El Cigarralejo (Cuadrado, E., 1987); la Dama sedente nutricia de Alcoy, de producción local (Marín Ceballos, A., 1987, 63); y las piezas del santuario de Coimbra del B. A. (Jumilla, Murcia).

De lo expuesto parece desprenderse que, entre los siglos IV-I a. C., el territorio sur de la Contestania está definido en un área en torno a Elche, que abarca las costas meridionales de Alicante y la cuenca del Segura, hasta Archena, rodeada por un área de influencia, relacionada directa o indirectamente con Ilici (figura 8).

Un interrogante que surge, tras esta exposición, es que las fuentes literarias más modernas citan como ciudades contestanas, entre otras, Dianium y Saitabi. O bien las consideramos no contestanas, o bien habría que plantearse que la Contestania está fragmentada en dos zonas, como ocurriera en la Fase Antigua. Una septentrional, en torno a Saitabi (Gil Mascarell, M., 1980) o Bocairente (Domínguez Monedero, A., 1984), y otra meridional en torno a Elche. Esta última, como sugiere Abad (en prensa), desborda el Vinalopó para adentrarse por el cauce del Segura, hasta Archena.

5 Estos pebeteros se documentan más al norte, dejando un vacío entre ambas zonas, que permite individualizar la región sureste. 

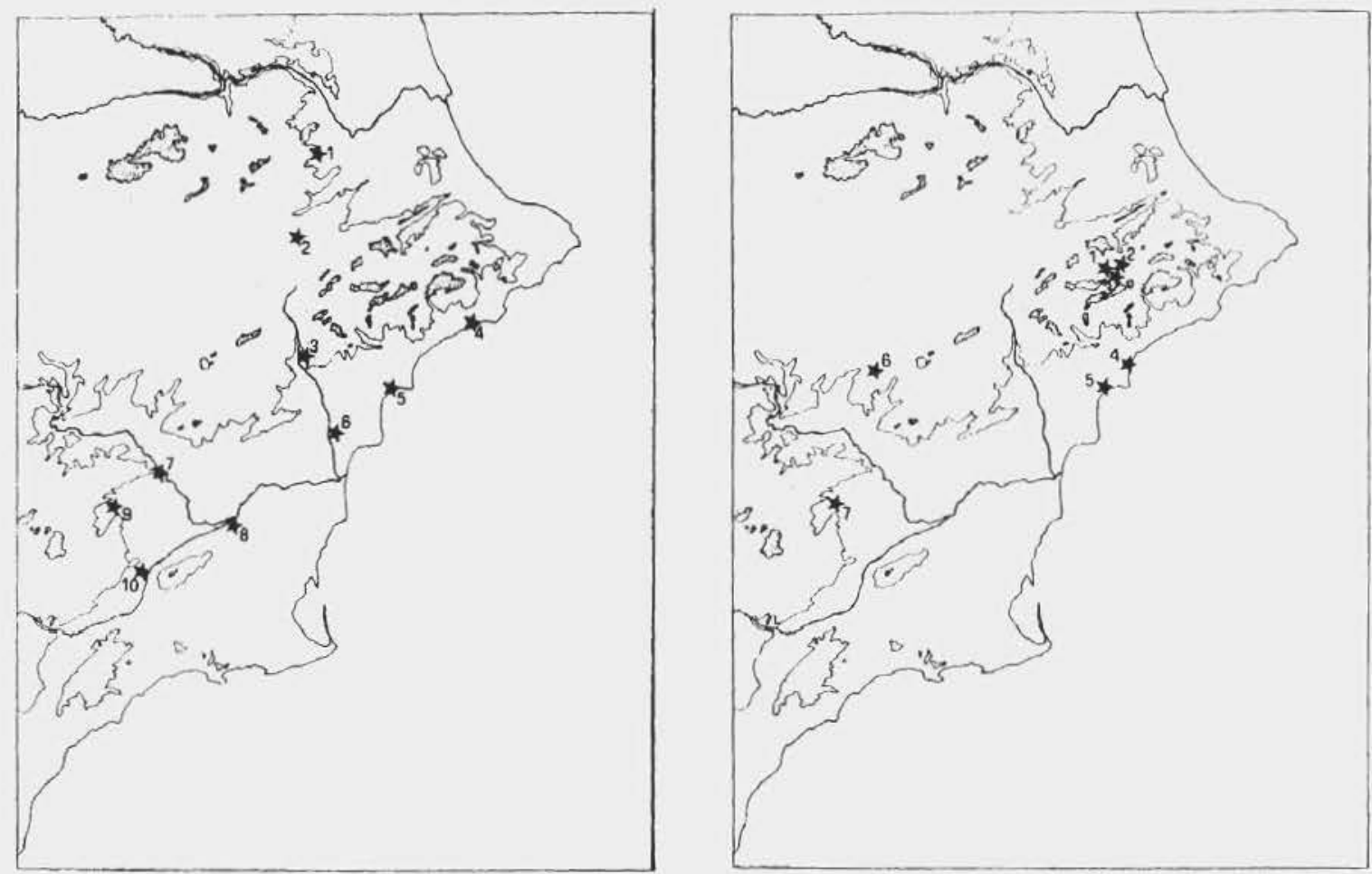

Figura 5.-Dispersión de los kalathoi «sombrero de copa» de estilo Elche y afines. 1: Enguera; 2: Corral de Saus; 3: El Monastil; 4: Benidorm; 5: La Albufereta; 6: Elche; 7: Archena; 8: Cabecico del Tesoro; 9: El Cigarralejo; 10: Alhama.

Figura 6.-Documentos escritos en alfabeto greco-ibérico. 1: La Serreta; 2: El Puig; 3: Mas de Is; 4: Campello; 5: Tossal de Manises; 6: Coimbra del B. A.; 7: El Cigarralejo.

Uno de los aspectos más interesantes, a tener en cuenta, es que los criterios para establecer los límites del territorio ilicitano, son manifestaciones de alta cultura (moneda, escritura). En tanto que otros, de carácter iconográfico, están ligados a la superestructura ideológica (pebeteros de cabeza femenina, damas nutricias sedentes o estantes y los motivos de la cerámica pintada). En estos casos no debemos sorprendernos, pues sabemos que sus más característicos elementos icónicos están vinculados entre sí. De hecho ya Olmos los había relacionado, partiendo de la base de que todas estas representaciones figuradas citadas presentan siempre los mismos elementos: busto (anodos), frontalidad, pájaros y espigas (Olmos, R., 1990, 20). Estamos probablemente ante una deidad local de la fecundidad y de la muerte, que ha sufrido el sincretismo con la púnica Tanit, de la que, por otra parte, sabemos de su identificación con la Juno romana, y recordemos que los semises de Ilici de 13-12 a. C. llevan un templo tetrástilo, con la inscripción IUNONI (Marín Ceballos, M., 1987, 68).

En otras palabras, no sólo se puede definir un área económica homogénea, sino también cultural y política, establecida sobre la base de una cohesión de carácter religioso, exponente de un culto ciudadano, centrado en Elche y su territorio. Ciudad y estado, en el caso ilicitano, se manifiestan de forma embrionaria y con un fuerte grado de aculturación helénico y fenicio-púnico. Elemento, este último, que hay que volver a reinvindicar en la formación y desarrollo de la cultura ibérica del sureste, pues no sólo lo apreciamos en los elementos referidos, sino también 
en obras como la esfinge del Parque infantil de Elche (Marín Ceballos, M., 1987, 66), o el monumento de Benejúzar del siglo III a. C. y claro influjo púnico (Chapa, T., 1986, 246 y Ramos Fernández, A., 1989).

LA CRISIS DE FINES DEL SIGLO IV A. C.:

\section{LA CONSOLIDACIÓN DEL MODELO ARISTOCRÁTICO Y LA CONCRECIÓN DEL TERRITORIO}

El tema del período crítico que sufre la cultura ibérica a fines del siglo IV a. C. es, en cierto modo, recurrente en la bibliografía, desde que en 1961 Tarradell publicara su conocido Ensayo de estratigrafía comparada, donde propone como causa de aquella crisis los efectos, sobre la península ibérica, del segundo tratado romano-cartaginés de 348 a. C. (Tarradell, M., 1961, 19). En la actualidad se vuelve sobre la propia dinámica de cambio del mundo ibérico, planteándose la posibilidad de una coyuntura económica inestable (Ruíz Mata, D., 1985-87, 304), que provoca un reajuste, con la aparición de un nuevo sistema de estados en la segunda mitad del siglo III a. C. (Ruiz, A., et al., 1991, 32).

La crisis se hace patente en el registro arqueológico, básicamente, a través de dos parámetros:

1) La práctica total desaparición de las cerámicas de importación.

2) El abandono de ciertos poblados y necrópolis.

1) Desde 350 a. C. en adelante se aprecia un importante descenso de las importaciones de cerámicas áticas, cuyo comercio había llegado a su cénit, poco antes, entre 375-350 a. C. Durante el tercer cuarto del siglo IV a. C. todavía llegan piezas en un número significativo, aunque muy reducido, para desaparecer prácticamente entre 325-300 a. C. Como explicación se han invocado, de nuevo, los efectos del II Tratado entre Roma y Cartago. Probablemente ésta sea una razón entre otras, algunas de las cuales se nos escapan.

De hecho, este comercio de vasos griegos desciende bruscamente, pero no desaparece, en la segunda mitad del siglo IV a. C.; y si tenemos en cuenta que los púnicos actuaron de intermediarios, a juzgar por lo que se desprende de las excavaciones del pecio de El Sec (Arribas, A., et al., 1988), tendríamos que pensar que no habría razón para terminar con esa corriente comercial, en las áreas meridionales de la península ibérica, de dominio púnico, ya que antes y después del tratado seguirían siendo ellos (los púnicos) quienes comerciarían con las cerámicas griegas.

La explicación de estos acontecimientos pueden estar en varias circunstancias, de carácter muy diverso, que convergen grosso modo entre 350-300 a. C.

Por un lado, la producción de cerámicas áticas, como objeto de lujo, que se exporta masivamente por el Mediterráneo, padece una crisis abierta tras las guerras del Peloponeso. En la figura 9 se aprecia el descenso paulatino del número de vasos de barniz negro en el Agora de Atenas, entre fines del siglo V y fines del IV a. C. (Sparkes, y Talcott, 1970). Si comparamos ese cuadro con el de las importaciones de El Cabecico del Tesoro (García Cano, J. M., et al., 1989) ${ }^{6}$ vemos

6 El cuadro de las importaciones de esta necrópolis nos sirve como marco global regional, pues su comportamiento es, a grandes rasgos, el mismo. 

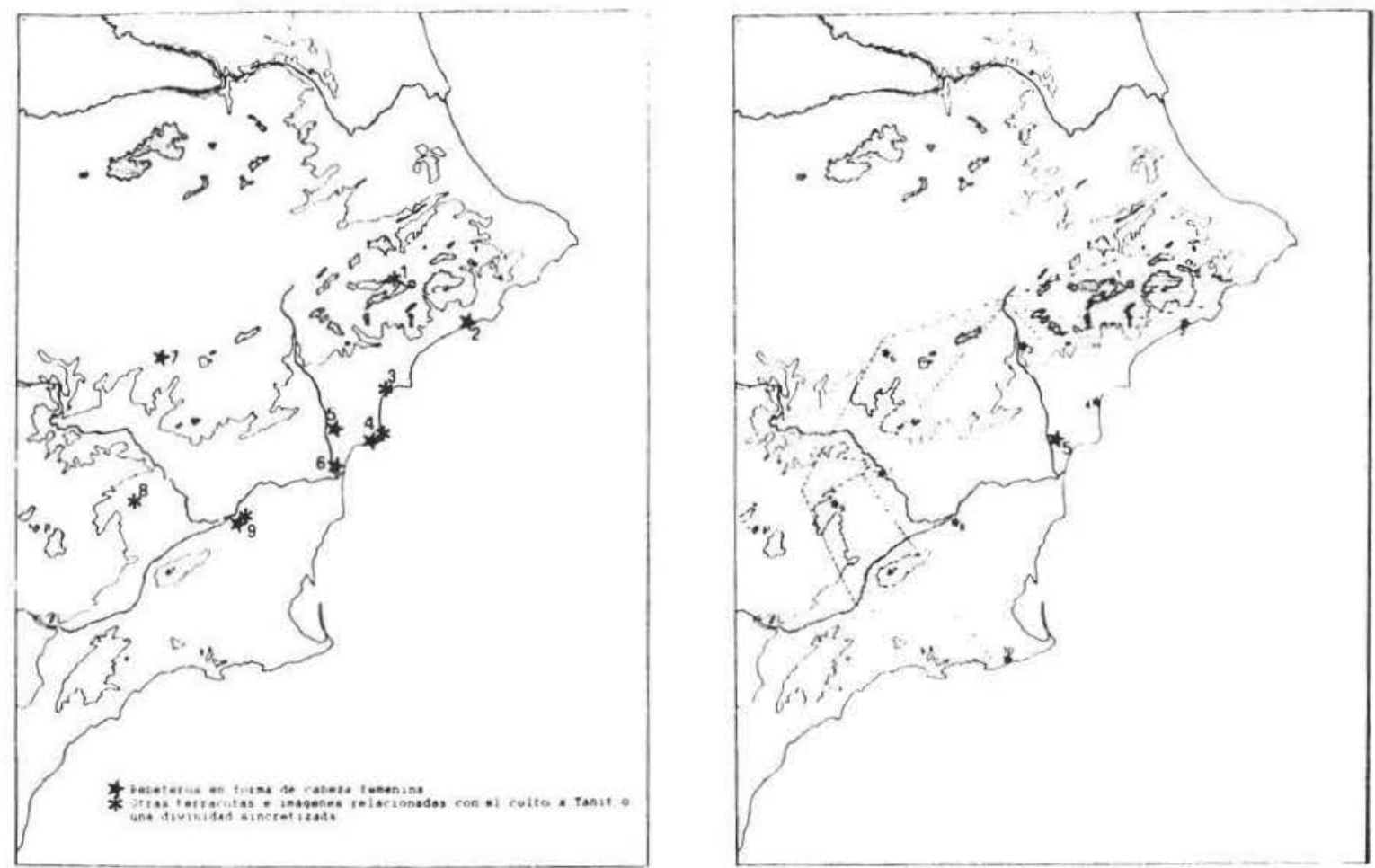

Figura 7.-Pebeteros y terracotas relacionadas con un posible culto a Tanit o un culto sincrético. I: Alcoy; 2: Benidorm; 3: Illeta de Campello; 4: La Albufereta; 5: Elche; 6: Guardamar; 7: Coimbra del Barranco Ancho; 8: El Cigarralejo; 9: Cabecico del Tesoro.

Figura 8.-Propuesta de ámbito territorial de Elche y su área periférica de influencia (en rayado horizontal). Localización de algunos de sus centros más significativos. 1: Alcoy; 2: Benidorm; 3: El Monastil; 4: La Albufereta; 5: La Alcudia; 6: Coimbra del B. A.; 7: Cabezo del Tío Pío; 8: Cabecico del Tesoro; 9: El Cigarralejo; 10: Cartagena.

unas circunstancias peculiares. La mayor profusión de barniz negro en Atenas se da en el último cuarto del siglo V. a. C., cuando en la península ibérica todavía se importan pocas piezas. Sin embargo, en el Agora la producción datable en los dos cuartos de siglo siguientes (400-350 a. C.), desciende, siendo, por el contrario, el momento de apogeo de la presencia de barniz negro ático en nuestra península. La investigación es unánime a la hora de explicar este fenómeno, por el cambio de mercados de los productos atenienses. Si en el siglo $\mathrm{V}$ a. C. su principal comprador es el mundo itálico, tras las guerras del Peloponeso, que finalizan en 404 a. C., los productos áticos deben buscar nuevos mercados en la periferia (la península ibérica y el Mar Negro).

A partir de 350 a. C. vemos cómo decae paulatinamente la producción ateniense, mientras que en Iberia caen las importaciones de una manera brusca, en la segunda mitad del siglo IV a. C. Podemos barajar dos posibles explicaciones, bien los talleres áticos han buscado nuevos compradores, desplazando sus productos a otros lugares, fuera de nuestra península (referencia oral de la Dra. C. Sánchez Fernández), bien una coyuntura de crisis, económica o social, interna provoca el colapso de los mercados ibéricos, que dejan de comprar los vasos griegos. 

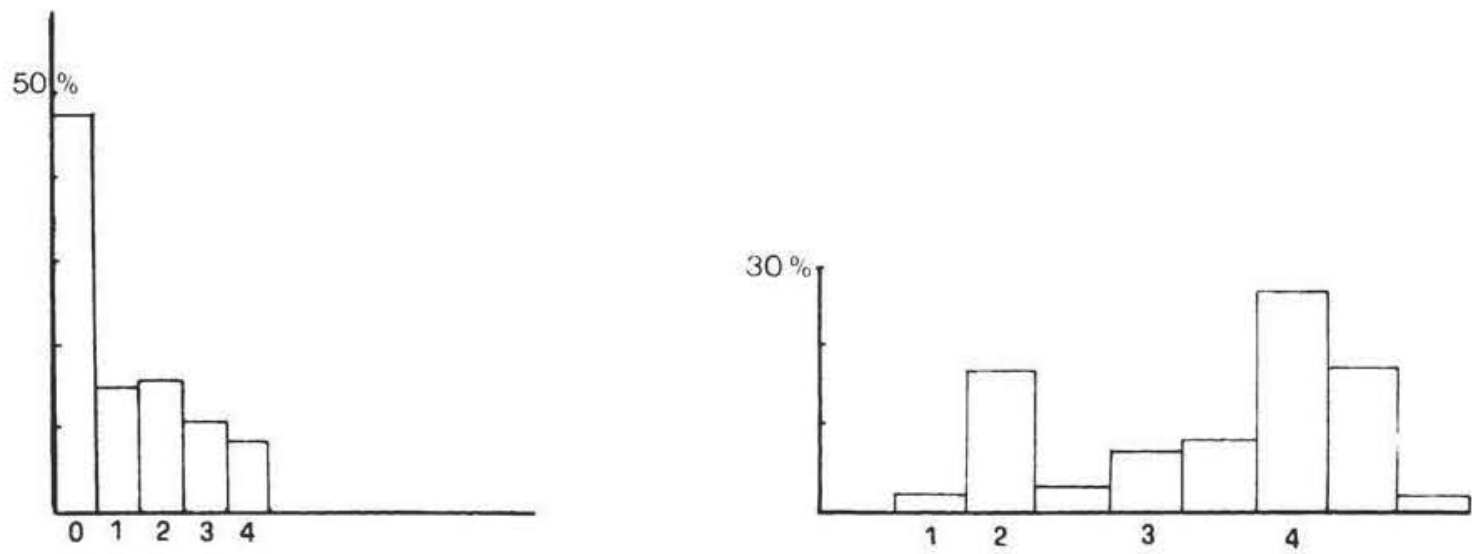

Figura 9.-A: Porcentajes de productos de barniz negro en el Ágora de Atenas. 0: 425-400 a. C.; 1: 400375 a. C.; 2: 375-350 a. C.; 3: 350-325 a. C.; 325-300 a. C.B: Porcentajes de productos de barniz negro en la necrópolis del Cabecico del Tesoro (según García Cano et al., 1989). 1: Fines del siglo V a. C.; 2: primera mitad del siglo IV a. C.; 3: primera mitad del siglo III a. C.; 4: primera mitad del siglo II a. C.

Ahora bien, al margen de ésto no hay que olvidar la situación que viven Cartago y el mundo púnico, por esos años, pues ellos actúan como intermediarios. Entre 409 y 367 a. C. se abre un período de guerras en Sicilia, que bien pudieron interferir en el normal desarrollo del comercio intermediterráneo en occidente. En 367 a. C. se consolidan las nuevas fronteras entre griegos y púnicos, en Sicilia (Moscati, S., 1988, 58) y hay un momento de tranquilidad, hasta que se reanudan los conflictos entre 342 y 339 a. C. Aquel período de calma (367-342 a. C.) coincide, a grandes rasgos, con el segundo cuarto del siglo IV a. C., momento de apogeo de las importaciones áticas en la península ibérica. Mientras que los períodos bélicos, contra Agatocles de Siracusa, entre 342-339 a. C. y 318-305 a. C., coinciden, el primero con el brusco corte de las importaciones en los mercados ibéricos hacia 350 a. C. aproximadamente, y el segundo con la propia decadencia final de los talleres atenienses y el fin de la llegada de vasos áticos a nuestra península. Tal vez sea la combinación de todos estos elementos externos e internos lo que nos acerque a una mejor comprensión de aquel período crítico.

2) En torno a 325 a. C. se abandonan parte de los hábitats y necrópolis ibéricas. Unos vuelven a reutilizarse a partir de la segunda mitad del siglo siguiente, otros son destruidos o abandonados definitivamente.

Podemos englobar los yacimientos de la región, de los que contamos con dataciones más seguras, en tres grupos, siguiendo aquel criterio.

a) Yacimientos que se abandonan definitivamente hacia 325 a. C.: Los Saladares (Orihuela), Cabezo de la Rueda (Alcantarilla), Los Molinicos (Moratalla), Ascoy (Cieza), La Bastida (Mogente), Cabezo Lucero (Rojales), El Puig (Alcoy) y la Illeta de Campello.

b) Yacimientos que padecen la crisis, pero reanudan su ocupación hacia 200 a. C.: Cabezo del Tío Pío (Archena), Cobatillas la Vieja (Cobatillas), Las Cabezuelas (Totana), el Cigarralejo (Mula), Castillico de los Baños (Fortuna), Bolbax (Cieza), El Xarpolar (Margarida) y El Castillo de Aspe. 
(c) Yacimientos que no presentan muestras claras de haber vivido la crisis, pues en ellos se documentan abundantes materiales de importación de los talleres protocampanienses del siglo III a. C. : La Serreta (Alcoy), Cabecico del Tesoro (Verdolay), Coimbra del Barranco Ancho (Jumilla), La Covalta (La Albaida), La Escuera, La Albufereta, Tossal de Manises (Alicante), El Monastil (Elda), El Campet (Monfort) y Los Nietos (Cartagena).

En la figura 10 vemos la localización de los lugares citados con anterioridad; en él apreciamos lo siguiente:

La primera mitad del siglo IV a. C. es un momento de expansión, puesto que la mayoría de yacimientos cuentan con materiales de ese período. La crisis de fines del siglo no parece vivirse con igual intensidad, en todas partes. Vemos que los centros en los que no se percibe con claridad aquel fenómeno de recesión son lugares, en su mayor parte, en el curso del Vinalopó o en la costa, próximos a Elche. Sólo Coimbra del B. A., Los Nietos y Cabecico del Tesoro se hallan más alejados. Al mismo tiempo se abandonan definitivamente o padecen la crisis una larga serie de yacimientos situados en los cauces del Segura, Mula y Guadalentín, más alejados del centro principal, Elche. Ello sugiere una reestructuración del modelo de ocupación del territorio, con el abandono de ciertos centros secundarios y la concentración de la población en lugares como Coimbra del B. A., Verdolay o Los Nietos.

Por último, observamos que, entre fines del siglo III a. C., y comienzos del siglo siguiente, se reanuda la vida de un conjunto de yacimientos que describen un gran arco, que prácticamente incluye el área del Vinalopó y el curso del Segura hasta Archena, precisamente el territorio propuesto como ámbito geográfico ligado política y económicamente a Elche, en el apartado anterior.

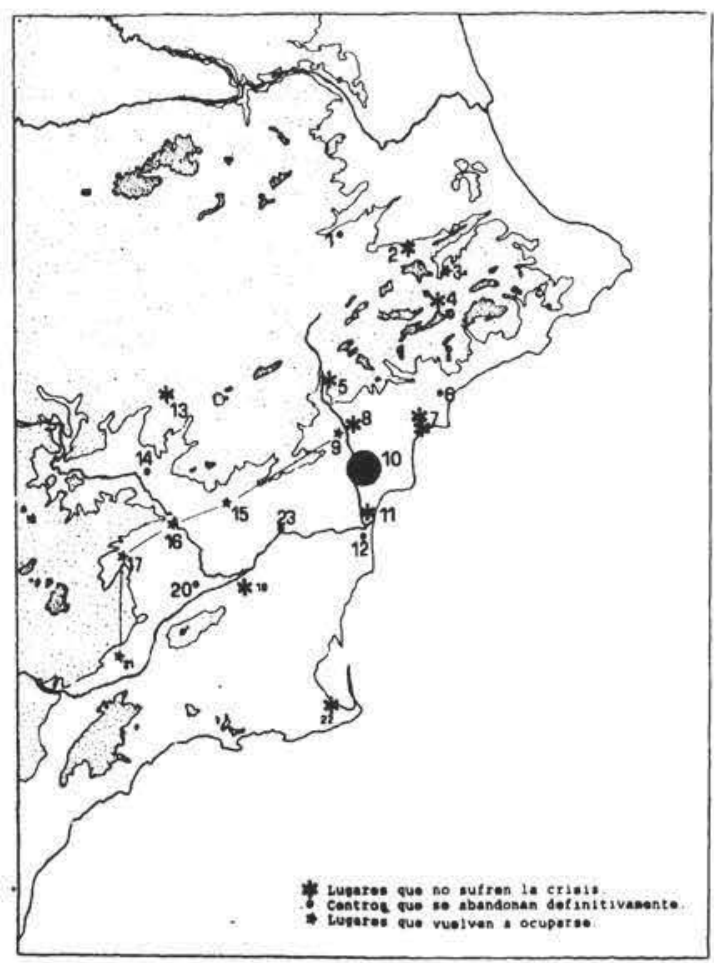

Figura 10.-Distribución de los yacimientos en el área estudiada y la crisis de fines del siglo IV a. C. (hipótesis de trabajo). 1: La Bastida; 2: La Covalta; 3: El Xarpolar; 4: Alcoy; 5: El Monastil; 6: Illeta de Campello; 7: La Albufereta y Tossal de Manises; 9: Castillo de Aspe; 10: La Alcudia; 11: La Escuera; 12: Cabezo Lucero; 13: Coimbra del B. A.; 14: Bolbax; 15: Cobatillas la Vieja; 16: Cabezo del Tío Pío; 17: El Cigarralejo; 18: Los Molinicos; 19: Cabecico del Tesoro; 20: Cabezo de la Rueda; 21: Alhama; 22: Los Nietos; 23: Los Saladares. 
En consecuencia se puede sugerir como hipótesis ${ }^{7}$ que las formas de poder aristocrático que se consolidan en la primera mitad del siglo IV a. C., basadas en la preeminencia de unos linajes dominantes, que podemos identificar en las tumbas principescas de necrópolis como El Cigarralejo, Coimbra del B. A., etc., entran en crisis a fines de ese siglo ${ }^{\star}$. Ahora bien, cuando volvemos a encontrar abundante documentación arqueológica y literaria, hacia 250-200 a. C., apreciamos una continuidad de las antiguas formas aristocráticas de poder dominantes. Se aprecia en el retrato de las comunidades indígenas que hacen las fuentes literarias; en la iconografía de los vasos pintados de Liria; en las tumbas tardías de grandes guerreros como la Tumba 0 de Hoya de Sta. Ana (Cabré, J., 1947), la tumba 27 de El Cabecico del Tesoro, de 300-250 a. C.; o la tumba de cámara de Toya de alrededor de 300. a. C. Además, el armamento continúa siendo el mismo, ligero, prehoplítico, y con igual abundancia de armas en las tumbas tardías, como se ha demostrado recientemente en el Cabecico del Tesoro (Quesada, F., 1989). Dato éste que contradice la idea tradicional de la casi total ausencia de armas en las tumbas de la Baja Epoca, que se interpretaba como la pérdida de vigencia de la clase guerrera dominante, tan característica de la Fase Plena.

Acontecimientos semejantes a éstos han sido interpretados en Andalucía oriental como el agotamiento del modelo nuclearizado y la resolución y definición de nuevos grupos (oretanos, bastetanos), que se vinculan a un oppidum homónimo (Oretum, Basti), que en esta región del sureste se entendería, de acuerdo con nuestra hipótesis, como la reorganización de un área de dominio en torno a Elche, paralelo a la definición de un modelo de estado aristocrático protourbano, que controla un territorio más o menos amplio, comprendido entre las costas meridionales de la actual provincia de Alicante y las cuencas del Vinalopó y del Segura, hasta Archena. Fenómeno parejo a su vez al de la definición de la Contestania meridional, tal y como nos llega a través de las fuentes escritas más modernas, que citan hasta Cartago Nova dentro de sus límites.

\section{BIBLIOGRAFÍA}

ABAD, L. (1985-87): «El poblamiento ibérico en la provincia de Alicante», I Jornadas sohre Mundo lhérico, Jaén.

ABAD, L. (en prensa): «Los pueblos prerromanos del Sureste y Levante», en Paletnología de la península Ibérica, Madrid.

Almagro, M. y Domínguez de LA CONCHA, A. (1988-89): «El palacio de Cancho Roano y sus paralelos arquitectónicos y funcionales, Zephyrus, XLI-XLII, Salamanca.

ARANEguI, C. (1988): «Algunes questions entorn de la historia de Sagunt», Fonaments, 7, Barcelona.

ARANEGUI, C. (en prensa): «La necrópolis ibérica de Cabezo Lucero (Alicante)" en Coloquio Internacional de Ampurias: griegos e iberos, Ampurias, 1991.

7 Hipótesis preliminar de trabajo a refrendar o refutar con un estudio exhaustivo del territorio y su poblamiento.

8 Para esta hipótesis son de gran valor los datos con que contamos en la provincia de Jaén donde se observa, en las gráficas de pólenes de Puente Tablas, una caída de uso del suelo, en ese período (Ruíz, A., et al., 1991, 32). 
Arribas, A. et al. (1987): El harco de El Sec (Calviá. Mallorca). Palma de Mallorca.

ARTEagia, O, y SERnA, M. R. (1975): «Los Saladares 71», Noticiario Arqueológico Hispano, 3, Madrid.

BERNABEU, J. et al. (1986), «Análisis microespacial del poblado ibérico del Puntal dels Llops (Olocau. Valencia)", Arqueología Espacial, vol. 9. Teruel.

BURILL.O, F. (1986): Aproximación diacrónica a las ciudades antiguas del valle medio del Ebro. Teruel.

CONDE, M. J. (1990): «Los kalathoi sombrero de copa de la necrópolis del Cabecico del Tesoro (Verdolay, Murcia)", Verdolay: 2, Murcia.

CUADRADO, E. (1987): La necrópolis ibérica de El Cigarralejo (Mula, Murcia), B. P. H.. XXIII, Madrid.

CHAPA, T. (1984): La escultura ibérica zoomorfa. Madrid.

CHAPA, T. (1986): Influjos griegos en la escultura ibérica zoomorfa, Madrid.

DOMínguez MONEDERO, A. (1984): «La escultura animalística ibérica contestana como exponente del proceso de helenización del territorio", Arqueología espacial, vol. 4, Teruel.

GARCÍA CANO. J. M. (1982): Las cerámicas griegas de la región de Murcia, Murcia.

GARCía CANO, J. M. y PAGE, V. (1990): «La necrópolis ibérica de Archena. Revisión de los materiales y nuevos hallazgos», Verdolay, 2, Murcia.

Garcia CANO, J. M. et al. (1989): «Las cerámicas campanienses del Cabecico del Tesoro (Verdolay, Murcia)", Verdolay, 1, Murcia.

Gil. MASCARELl., M. (1980): «Notas acerca del poblamiento ibérico en el País Valenciano», I Congreso de Historia del País Valenciano, vol. 2, Valencia.

GÓmez Bellard, C. y GUeRIN, P. (en prensa): «L'Alt de Benimaquia», en Coloquio internacional de Ampurias: griegos e iberos, Ampurias, 1991.

GUERIN P., BONET, H. y MATA, C. (1989): «La deuxième guerre punique dans l'est ibérique à travers les données archéologiques", Studia Phoenicia, X, Leuven.

JACOB, P. (1985): «Le rôle de la ville dans la formation du peuple ibère», Mélanges de la Casa de Velázquez, XXI, París.

LILLo, P. (1981): El poblamiento ibérico en Murcia, Murcia.

LLOBREGAT, E. (1972): Contestania ibérica, Alicante.

LLOBREGAT, E. (1988), «Un conjunto de templos ibéricos del siglo IV a. C. hallados en la isla de Campello», en Homenaje a $S$. de los Santos, Albacete.

LLORENS, M. (1987): La ceca de llici, Valencia.

Marín Ceballos. M. C. (1987): « ¿Tanit en España?», Lucentum, VI, Alicante.

MENÉNDEZ, M. (1988): La cerámica ibérica del llamado estilo Elche-Archena, Madrid.

MoscATI, S. (1988), «L'impero di Cartagine», en I Fenici, Milán.

OLMOS, R. (1990): «Original elements and mediterranean stimuli in iberian pottery», Mediterranean Archaeology, 3 .

PovedA, A. (1988): El poblamiento ibérico de El Monastil, Elda.

RAmOS Folques, A. y RAMOS FERNÁNDEZ, R. (1976): «Excavaciones al este del Parque Infantil de Tráfico de Elche (Alicante)", Noticiario arqueológico Hispánico, 4.

RAMOS FERNÁNDEZ, R. (1989): «Vestigios de un posible monumento funerario ibérico en el parque de Elche», Congreso Nacional de Arqueología, XIX.

Ruíz MATA, D. (1985-87): «La formación de la Cultura Turdetana en la bahía de Cádiz a través del Castillo de Doña Blanca", I Jornadas sobre Mundo Ibérico, Jaén.

Ruíz RodRígueZ, A. (1978): «Los pueblos ibéricos del Alto Guadalquivir. Análisis de un proceso de transición", Cuadernos de Prehistoria de la Universidad de Granada, 3, Granada.

RUIZ, A., MolinOS, M. y CASTRO, M. (1991): «Settlement and continuity in the territory of de Guadalquivir Valley (6thBC-1st century Ad.), en Roman landscapes, eds. G. Barker y J. Lloyd, Londres.

SANTOS VelașCO, J. A., (1989a), «Análisis sobre la transición a una sociedad estatal en la cuenca media del Segura, en época ibérica», Trabajos de Prehistoria, 46, Madrid. 
Santos Velasco, J. A. (1989b), «Análisis social de la necrópolis de El Cigarralejo y otros contextos funerarios de su entorno", Archivo Español de Arqueología, 62, Madrid.

SANTOS Velasco, J. A. (en prensa): «Ciudad y estado ibéricos del sureste peninsular, en el ámbito mediteráneo».

SPARKES, T. y TAlCOTT, V. (1970): Black and plain pottery. Athenian Agora. vol. XII, Princeton.

TARRADELL, M. (1961): «Ensayo de estratigrafía comparada y de cronología de los poblados ibéricos valencianos", Saitabi, XI, Valencia. 
Archivo Español de Arqueología, 65, 1992, 33-47 